\title{
Kajian Awal Kebutuhan Fasilitas Kesehatan Tingkat Lanjut (FKTL) di Pedalaman Kabupaten Ketapang
}

\author{
Edward Hartono \\ Fakultas Kedokteran Universitas Katolik Soegijapranata Semarang \\ email: edward@unika.ac.id
}

\begin{abstract}
Abstrak
Panduan dari WHO atas kebutuhan Tempat Tidur Fasilitas Kesehatan Tingkat Lanjut(FKTL) adalah 1:1.000 jiwa penduduk maka perlu dikaji untuk penambahan FKTL. Adapun kajian awal ini dengan memakai panduan variabel dari Studi Kelayakan Pembuatan FKTL dalam hal ini Rumah Sakit untuk mengkaji kebutuhan FKTL khususnya di daerah pedalaman Kabupaten Ketapang. Tujuan studi awal ini untuk mengetahui kebutuhan dan estimasi lokasi FKTL di wilayah Pedalaman dengan membagi wilayah pedalaman menjadi tiga bagian yaitu utara, tengah dan selatan atas dasar jalur akses transportasi darat. Metode yang digunakan adalah telaah dokumen dari profil kesehatan Kabupaten Ketapang 2019, Kabupaten Ketapang Dalam Angka 2020. Telaah dokumen dengan skoring menghasilkan kecamatan Sandai, Simpang Laur untuk wilayah Utara, Kecamatan Nanga Tayap untuk wilayah tengah dan Kecamatan Air Upas untuk wilayah selatan pedalaman sebagai usulan untuk pembuatan FKTL.
\end{abstract}

Kata kunci : Fasilitas Kesehatan Tingkat Lanjut, Pedalaman

\begin{abstract}
The guidance from WHO on the need for Advanced Health Facilities (FKTL) Hospital Beds are 1: 1.000 population so it needs to be assessed for the addition of FKTL. As for this preliminary study using the variable guidance from the Feasibility Study of Making FKTL in this case the Hospital to assess the needs of FKTL especially in the remote areas of Ketapang Regency. The purpose of this preliminary study is to determine the needs and estimation of FKTL locations in the remote areas by dividing the inland areas into three parts, namely north, central and south on the basis of land transportation access points. The method used is a document review of the health profile of Ketapang Regency 2019, Ketapang Regency in Figures 2020. The scoring document review produced Sandai and SimpangLaur sub-district for the North, Nanga Tayap Sub-district for the central region and Air Upas Sub-district for the southern remotes region as a proposal for the FKTL development.
\end{abstract}

Keywords : Advanced Health Facilities, Remote Areas

\section{PENDAHULUAN}

Penduduk di Kabupaten Ketapang berdasarkan data profil kesehatan kabupaten Ketapang 2019 sebesar 512.783 jiwa dengan angka pertumbuhan $2 \%$. menurut data maka wilayah Kabupaten Ketapang yang terdiri dari 20 kecamatan dibagi menjadi tiga wilayah yaitu kota, pantai dan pedalaman. Adapun kecamatan yang tercakup dalam wilayah kota adalah delta Pawan, Muara Pawan dan Benua Kayong. Wilayah pantai meliputi cakupan kota yang sebelumnya disebutkan ditambah dengan kecamatan Kendawangan, Matan hilir Utara dan Matan Hilir Selatan. Sedangkan yang tercakup dalam pedalaman adalah : Manis Mata, Air Upas, Tumbang Titi, Pemahan, Sungai Melayu Rayak, Nanga Tayap, Sandai, Sungai Laur, Simpang Hulu, Simpang Dua, Marau, Singkup, Jelai Hulu, Hulu Sungai. Jumlah penduduk yang termasuk dalam klasifikasi kota sebesar 144.547 jiwa. Untuk klasifikasi pantai sebesar 238.465 jiwa sudah 
termasuk penduduk kota yang letaknya juga di pantai. Sedangkan untuk kecamatan yang termasuk dalam klasifikasi pedalaman mempunyai penduduk sebanyak 274.318 jiwa.

Hal terkait pelayanan kesehatan di Kabupaten Ketapang maka dilayani oleh 2(dua) kategori fasilitas kesehatan yaitu fasilitas kesehatan Tingkat Pertama(FKTP) dan Fasilitas Kesehatan Tingkat Lanjut (FKTL). Fasilitas Kesehatan Tingkat Pertama (FKTP) yang dalam hal ini tersebar di seluruh kecamatan adalah puskesmas, terdiri dari 24 puskesmas yang tersebar di 20 kecamatan yang ada. adapun dari 24 puskesmas ini terdapat 8(delapan) puskesmas yang memiliki fasilitas rawat inap dasar yaitu puskesmas Kendawangan, Marau, Tumbang Titi, Sei Melayu, Nanga Tayap, Sandai, Sungai Laur dan Balai Berkuak. Sedangkan untuk fasilitas Kesehatan Tingkat Lanjut (FKTL) hanya ada 3 Rumah Sakit yaitu RSUD( 147 TT), RS Fatima(173) dan RSIA(35) dengan total tempat tidur sebanyak 355 TT ( data diambil dari Profil Kesehatan Kabupaten Ketapang 2019) dan ketiganya ada di kota Ketapang.

Menurut standar WHO disebutkan minimal 1 tempat tidur Rumah sakit untuk melayani 1.000 penduduk. Jika dilihat dari penduduk Kabupaten Ketapang maka didapatkan kebutuhan sebesar 513 tempat tidur dan baru diakomodir oleh 3 RS sebanyak 355 tempat tidur. Atas dasar data tersebut masih kekurangan 158 tempat tidur. Namun keseluruhan fasilitas kesehatan tingkat lanjut ini berpusat di kota Ketapang yang lokasi nya termasuk klasifikasi pantai. Sedangkan untuk penduduk sebesar 274.318 jiwa di pedalaman belum mempunyai fasilitas tersebut. Hanya dilayani oleh fasilitas kesehatan tingkat pertama(FKTP).

Oleh karena hal itu diperlukan adanya penambahan fasilitas kesehatan tingkat lanjut (FKTL) tipe D di wilayah wilayah kecamatan khususnya di wilayah klasifikasi pedalaman tanpa melupakan faktor akses, cakupan dan kebutuhan lainnya yang dapat ditelaah dalam sebuah studi kelayakan pembuatan Rumah Sakit.

\section{METODE}

Dalam kajian awal kebutuhan fasilitas kesehatan tingkat Lanjut(FKTL) di kabupaten Ketapang khususnya di wilayah pedalaman menggunakan data sekunder yang akan memberikan gambaran awal dengan telaah dokumen terkait demografi, geografi, ketenagakerjaan kesehatan, derajat kesehatan dan sarana kesehatan dalam pendirian FKTL dalam hal ini rumah sakit. Penelitian bersifat deskriptif dan jenis nya cross sectional. Wilayah pedalaman Kabupaten Ketapang dibagi menjadi tiga bagian berdasarkan akses jalan transportasi darat menjadi bagian utara, tengah dan selatan. Data sekunder yang ada dilakukan pemberian skoring untuk membantu menentukan pilihan prioritas. Pemberian skoring pada data demografi, geografi, ketenagakerjaan kesehatan, derajat kesehatan dan sarana kesehatan.

Pemberian skoring untuk demografi meliputi skoring untuk jumlah penduduk dan tingkat kepadatan penduduk. Pemberian skoring untuk jumlah penduduk berdasarkan nilai tengah dari jumlah penduduk dan skoring nya adalah $<9.637=0,9.637$ 19.274=1, 19.275-28.911 = 2, 28.912-38.548 $=3$. Sedangkan skoring untuk tingkat kepadatan penduduk adalah $<29,575=0$, $29,576-59,15=1, \quad 59,16-88,725=2, \quad 88,726-$ $118,3=3$. Total skoring untuk demografi adalah penjumlahan dari skoring yang didapatkan dari skoring jumlah penduduk dijumlah dengan skoring tingkat kepadatan penduduk.

Pemberian skoring untuk geografi berdasarkan jarak lokasi dan estimasi waktu tempuh berdasarkan acuan dari google maps. Jarak lokasi dan estimasi waktu tempuh yang ditentukan adalah estimasi jarak lokasi antara puskesmas masing-masing kecamatan. Skoring untuk estimasi jarak lokasi adalah $<50 \mathrm{~km} \quad=3, \quad 51-100 \mathrm{~km}=2, \quad 101$ $150 \mathrm{~km}=1, \quad>151 \mathrm{~km}=0$. Skoring untuk estimasi jarak tempuh adalah $<1$ jam $=3$, $1-1,5 \mathrm{jam}=2,1,5-2 \mathrm{jam}=1,>\quad 2 \mathrm{jam}=0$. Sehingga total untuk skoring geografi adalah 
Jurnal PRAXIS | Vol. 3 | No. 1 | September 2020

jumlah kedua skoring untuk masing-masing kecamatan.

Pemberian skoring untuk ketenagakerjaan kesehatan dibagi menjadi 3(tiga) skoring yaitu skoring untuk tenaga medis dokter dan dokter gigi, skoring untuk tenaga medis lainnya, dan tenaga struktural dan penunjang manajemen. Skoring untuk tenaga medis dokter dan dokter gigi adalah jumlah dokter $>2$ dan lengkap ada dokter dan dokter gigi=3, masing-masing ada 1 dokter $=2$, hanya ada salah satu $=1$, tidak ada dokter $=0$. Skoring untuk tenaga medis lainnya yang jenis pekerjaannya ada 10(sepuluh) jenis yang dilihat hanyalah kelengkapannya (kualitas) adalah lengkap semua ada $=3$, kurang satu $=2$, kurang $2=1$, kurang 3 atau lebih $=0$. Sedangkan skoring untuk tenaga struktural dan penunjang manajemen adalah jumlah tenaga struktural dan penunjang masing-masing minimal $2=3$, jika salah satu hanya ada $1=2$, jika salah satunya tidak ada $=1$, jika tidak ada keduanya $=0$.

Pemberian skoring derajat kesehatan dalam hal ini mengambil angka kematian bayi yaitu $0-9,765=3, \quad 9,766-19,53=2$, $19,54-29,295=1, \quad>=29,296=0$. Sedangkan pemberian skoring sarana kesehatan dilihat dari kelengkapan adanya puskesmas, puskesmas pembantu dan puskesmas rawat inap secara kualitasnya bukan kuantitasnya. Adapaun skoringnya adalah lengkap ketiganya ada $=3$, tidak ada puskesmas rawat inap $=2$, tidak ada puskesmas pembantu $=1$, tidak ada semuanya $=0$.

\section{HASIL}

\section{Demografi}

Berdasarkan data sekunder yang telah dilakukan skoring maka didapatkan sebagai berikut :

Tabel 1.

Skoring Demografi Pedalaman Bagian Utara

\begin{tabular}{cccc}
\hline Kecamatan & Skoring jumlah penduduk & $\begin{array}{c}\text { Skoring tingkat } \\
\text { kepadatan }\end{array}$ & total Skoring demografi \\
\hline Sandai & 3 & 0 & 3 \\
\hline Simpang hulu & 3 & 0 & 2 \\
\hline Sungai Laur & 2 & 0 & 1 \\
\hline Hulu Sungai & 1 & 0 & 0 \\
\hline Simpang dua & 0 & 0 & \\
\hline
\end{tabular}


Jurnal PRAXIS | Vol. 3 | No. 1 | September 2020

Tabel 2

Skoring Demografi Pedalaman Bagian Tengah

\begin{tabular}{lccc}
\hline \multicolumn{1}{c}{ Kecamatan } & $\begin{array}{c}\text { Skoring jumlah } \\
\text { penduduk }\end{array}$ & $\begin{array}{c}\text { Skoring tingkat } \\
\text { kepadatan }\end{array}$ & total Skoring demografi \\
\hline Sungai melayu Rayak & 1 & 3 & 4 \\
\hline Nanga Tayap & 3 & 0 & 3 \\
\hline Tumbang Titi & 2 & 0 & 2 \\
\hline Pemahan & 0 & 0 & 0 \\
\hline
\end{tabular}

Tabel 3

Skoring Demografi Pedalaman Bagian Selatan

\begin{tabular}{lccc}
\hline Kecamatan & Skoring jumlah penduduk & $\begin{array}{c}\text { Skoring tingkat } \\
\text { kepadatan }\end{array}$ & total Skoring demografi \\
\hline Air upas & 2 & 2 & 4 \\
\hline Manismata & 3 & 0 & 3 \\
\hline Jelai Hulu & 1 & 0 & 1 \\
\hline Marau & 1 & 0 & 1 \\
\hline Singkup & 0 & 0 & 0 \\
\hline
\end{tabular}

Geografi

Berdasarkan data yang sudah diberikan skoring maka didapatkan sebagai berikut

Tabel 4

Skoring Geografi Pedalaman Bagian Utara

\begin{tabular}{cccc}
\hline Kecamatan & Skoring waktu & Skoring Jarak & Skoring Geografi \\
\hline Sungai Laur & 9 & 10 & 19 \\
\hline Sandai & 7 & 9 & 16 \\
\hline Simpang dua & 7 & 8 & 12 \\
\hline Hulu Sungai & 4 & 8 & 11 \\
\hline Simpang hulu & 5 & 6 & \\
\hline
\end{tabular}


Tabel 5

Skoring Geografi Pedalaman Bagian Tengah

\begin{tabular}{cccc}
\hline Kecamatan & Skoring waktu & Skoring Jarak & Skoring Geografi \\
\hline Pemahan & 9 & 9 & 18 \\
\hline Tumbang Titi & 8 & 9 & 17 \\
\hline $\begin{array}{c}\text { Sungai Melayu } \\
\text { Rayak }\end{array}$ & 8 & 9 & 17 \\
\hline Nanga Tayap & 7 & 9 & 16 \\
\hline
\end{tabular}

Tabel 6

Skoring Geografi Pedalaman Bagian Selatan

\begin{tabular}{cccc}
\hline Kecamatan & Skoring waktu & Skoring Jarak & Skoring Geografi \\
\hline Air Upas & 8 & 12 & 20 \\
\hline Marau & 7 & 11 & 18 \\
\hline Jelai Hulu & 6 & 10 & 16 \\
\hline Singkup & 5 & 10 & 15 \\
\hline Manismata & 2 & 9 & 11
\end{tabular}

\section{Ketenagakerjaan kesehatan}

Berdasarkan data yang dilakukan skoring didapatkan hasil sebagai berikut Tabel 7.

Skoring Ketenagakerjaan Kesehatan Pedalaman Bagian Utara

\begin{tabular}{ccccc}
\hline Kecamatan & Dokter & Tenaga Medis Lain & Tenaga Struktural & Total Skoring \\
\hline Sandai & $\mathbf{3}$ & $\mathbf{1}$ & $\mathbf{3}$ & $\mathbf{7}$ \\
\hline Simpang Hulu & $\mathbf{2}$ & $\mathbf{0}$ & $\mathbf{3}$ & $\mathbf{5}$ \\
\hline Hulu Sungai & $\mathbf{1}$ & $\mathbf{1}$ & $\mathbf{2}$ & $\mathbf{4}$ \\
\hline Sungai Laur & $\mathbf{2}$ & $\mathbf{0}$ & $\mathbf{2}$ & $\mathbf{4}$ \\
\hline Simpang Dua & $\mathbf{0}$ & $\mathbf{1}$ & $\mathbf{3}$ & $\mathbf{4}$ \\
\hline
\end{tabular}

Tabel 8 
Jurnal PRAXIS | Vol. 3 | No. 1 | September 2020

Skoring Ketenagakerjaan Kesehatan Pedalaman Bagian Tengah

\begin{tabular}{ccccc}
\hline Kecamatan & Dokter & $\begin{array}{c}\text { Tenaga Medis } \\
\text { Lain }\end{array}$ & Tenaga Struktural & Total Skoring \\
\hline nanga Tayap & $\mathbf{3}$ & $\mathbf{0}$ & $\mathbf{3}$ & $\mathbf{6}$ \\
\hline Tumbang Titi & $\mathbf{1}$ & $\mathbf{1}$ & $\mathbf{3}$ & $\mathbf{4}$ \\
\hline Pemahan & $\mathbf{1}$ & $\mathbf{0}$ & $\mathbf{3}$ & $\mathbf{3}$ \\
\hline Sei Melayu & $\mathbf{2}$ & $\mathbf{0}$ & $\mathbf{1}$ & \\
\hline
\end{tabular}

Tabel 9

Skoring Ketenagakerjaan Kesehatan Pedalaman Bagian Selatan

\begin{tabular}{ccccc}
\hline Kecamatan & Dokter & Tenaga Medis Lain & Tenaga Struktural & Total Skoring \\
\hline Air Upas & $\mathbf{2}$ & $\mathbf{1}$ & $\mathbf{3}$ & $\mathbf{6}$ \\
\hline Manis Mata & $\mathbf{2}$ & $\mathbf{0}$ & $\mathbf{3}$ & $\mathbf{5}$ \\
\hline Marau & $\mathbf{2}$ & $\mathbf{0}$ & $\mathbf{3}$ & $\mathbf{5}$ \\
\hline Jelai Hulu & $\mathbf{0}$ & $\mathbf{2}$ & $\mathbf{3}$ & $\mathbf{3}$ \\
\hline Singkup & $\mathbf{1}$ & $\mathbf{0}$ & $\mathbf{2}$ &
\end{tabular}

\section{Derajat kesehatan}

Angka kematian bayi mewakili derajat kesehatan dalam tulisan ini. Adapun data yang sudah diskoring adalah sebagai berikut :

Tabel 10

Skoring Derajat Kesehatan Pedalaman Bagian Utara

\begin{tabular}{cccccc}
\hline KECAMATAN & NEONATAL MATI & BAYI & AKB & TOTAL & SKORING \\
\hline Hulu Sungai & 0 & 0 & 0 & 0,00 & 3 \\
\hline Sungai Laur & 1 & 2 & 3 & 8,55 & 1 \\
\hline Simpang Hulu & 3 & 6 & 9 & 25,35 & 1 \\
\hline Sandai & 6 & 7 & 13 & 26,05 & 0 \\
\hline Simpang Dua & 2 & 3 & 5 & 39,06 & \\
\hline
\end{tabular}

Tabel 11 
Jurnal PRAXIS | Vol. 3 | No. 1 | September 2020

Skoring Derajat Kesehatan Pedalaman Bagian Tengah

\begin{tabular}{lccccc}
\hline \multicolumn{1}{c}{ KECAMATAN } & NEONATAL MATI & BAYI & AKB & TOTAL & SKORING \\
\hline Nanga Tayap & 1 & 1 & 2 & 5,29 & 3 \\
\hline Sungai Melayu Rayak & 0 & 2 & 2 & 8,55 & 2 \\
\hline Tumbang Titi & 3 & 3 & 6 & 13,36 & 0 \\
\hline Pemahan & 1 & 2 & 3 & 34,09 & 3 \\
\hline
\end{tabular}

Tabel 12

Skoring Derajat Kesehatan Pedalaman Bagian Selatan

\begin{tabular}{lccccc}
\hline \multicolumn{1}{c}{ KECAMATAN } & NEONATAL MATI & BAYI & AKB & TOTAL & SKORING \\
\hline Singkup & 0 & 0 & 0 & 0,00 & 3 \\
\hline Air Upas & 1 & 1 & 2 & 5,31 & 3 \\
\hline Manis Mata & 1 & 3 & 4 & 7,86 & 2 \\
\hline Marau & 1 & 2 & 3 & 12,30 & 0 \\
\hline Jelai Hulu & 3 & 5 & 8 & 27,03 &
\end{tabular}

\section{Sarana kesehatan}

Tabel 13

Skoring Sarana Kesehatan Pedalaman Bagian Utara

\begin{tabular}{lc}
\hline \multicolumn{1}{c}{ KECAMATAN } & SKORING \\
\hline Sandai & 3 \\
\hline Hulu Sungai & 2 \\
\hline Sungai Laur & 3 \\
\hline Simpang Hulu & 3 \\
\hline Simpang Dua & 2
\end{tabular}


Jurnal PRAXIS | Vol. 3 | No. 1 | September 2020

Tabel 14

Skoring Derajat Kesehatan Pedalaman Bagian Tengah

\begin{tabular}{lc}
\hline KECAMATAN & SKORING \\
\hline Tumbang Titi & 3 \\
\hline Pemahan & 2 \\
\hline Sei Melayu & 3 \\
\hline Nanga Tayap & 3 \\
\hline
\end{tabular}

Tabel 15

Skoring Derajat Kesehatan Pedalaman Bagian Selatan

\begin{tabular}{cc}
\hline KECAMATAN & SKORING \\
\hline Manis Mata & 2 \\
\hline Marau & 3 \\
\hline Air Upas & 2 \\
\hline Singkup & 2 \\
\hline Jelai Hulu & 2 \\
\hline
\end{tabular}

\section{PEMBAHASAN}

Berdasarkan hasil yang kita kumpulkan dari data sekunder maka kita bahas lebih detail untuk menentukan kebutuhan akan Fasilitas Kesehatan Tingkat Lanjut(FKTL). Dan dilanjutkan prioritas area lokasi FKTL tersebut. Adapun dalam hal ini faktor -faktor yang diperhitungkan dalam penentukan kebutuhan FKTL adalah demografi, geografi, ketenagakerjaan kesehatan, derajat kesehatan dan sarana kesehatan.

\section{Demografi}

Hasil gabungan skoring untuk demografi pedalaman bagian utara merupakan gabungan dari skoring jumlah penduduk dan tingkat kepadatan penduduk dan didapatkan skoring tertinggi diperoleh oleh Kecamatan Sandai dan Simpang Hulu dengan hasil skoring sama yaitu 3(tiga). Jika ditelaah lebih lanjut maka Kecamatan Sandai meski jumlah penduduknya beda sedikit dari Simpang Hulu namun tingkat kepadatannya 2,5x lebih padat dibandingkan Simpang Hulu. Hal ini membuktikan bahwa luas cakupan wilayah Sandai lebih kecil dan lebih banyak penduduk cakupan per $\mathrm{km} 2$ nya. Sehingga secara demografi lokasi dari Fasilitas Kesehatan Tingkat Lanjut(FKTL) untuk pedalaman bagian utara lebih baik di Kecamatan Sandai.

Skoring demografi pedalaman bagian tengah didapatkan skoring tertinggi adalah Kecamatan Sei Melayu Rayak. Dengan tingkat kepadatannya yang sekitara 6x lebih padat dibandingkan dengan kecamatan lainnya di wilayah tengah maka lokasi FKTL di wilayah tengah secara demografi adalah Sei Melayu Rayak. 
Skoring demografi pedalaman bagian selatan dengan skoring tertinggi adalah kecamatan Air upas. Tingkat kepadatan jika dibandingkan dengan yang lain di wilayah selatan sekitar 6-8x lebih padat maka lokasi FKTL scara demografi adalah di Kecamatan Air Upas.

\section{Geografi}

Berdasarkan geografinya maka yang digaris bawahi adalah estimasi jarak dan waktu tempuh untuk mencapai lokasi dengan transportasi darat dalam hal ini adalah kendaraan roda empat. Scoring yang didapatkan tertinggi untuk wilayah Utara adalah Kecamatan Sungai Laur. Hal ini menunjukkan lokasi Kecamatan Sungai Laur paling efisien untuk jarak dan waktu tempuh dari masing-masing kecamatan di wilayah kecamatan di pedalaman bagian utara. Sedangkan bagian tengah yang paling efisien secara waktu dan jarak adalah di Kecamatan Pemahan. Bagian selatan pedalaman yang mendapatkan skoring tertinggi terkait efisiensi jarak dan waktu tempuh adalah di Kecamatan Air Upas

\section{Ketenagakerjaan Kesehatan}

Ketenagakerjaan kesehatan kami bagi menjadi tiga bagian yaitu dokterdan dokter gigi, petugas medis dan petugas struktural dengan penunjang manajemen. Skoring tertinggi di pedalaman bagian utara terdapat di Kecamatan Sandai. Hal ini didukung kelengkapan dan kecukupan tenaga medis terutama untuk dokter dan tenaga struktural meskipun tenaga medis lainnya belum lengkap. Skoring tertinggi untuk bagian tengah adalah di Kecamatan Nanga Tayap. Sedangkan untuk bagian selatan adalah Keamatan Air Upas. Dari ketiga wilayah kelemahan terutama di kelengkapan dari tenaga medis lainnya diluar dokter . dari sepuluh(10) jenis tenaga medis lain diluar dokter masih ada kekurangan kelengkapan personelnya.

\section{Derajat Kesehatan}

Angka Kematian bayi menunjukkan tingkat sosial ekonomi masyarakat. Oleh karena itu semakin kecil angka kejadian kematian bayi maka merujuk tingginya sosial ekonomi masyarakat tempat itu. Bagian utara memiliki skoring tertinggi di Kecamatan Hulu Sungai dan Sungai Laur. Di bagian tengah Kecamatan Nanga Tayap dan Sei Melayu Rayak. Sedangkan selatan di Kecamatan Singkup.

\section{Sarana Kesehatan}

Sarana Kesehatan yang dinilai dari kelengkapan fasilitas kesehatan yang meliputi puskesmas, puskesmas pembantu dan puskesmas rawat inap. Faktor utama adalah adanya puskesmas rawat inap. Berdasarkan data yang ada yang meraih posisi pertama adalah di Kecamatan Sungai laur. Pada kelompok tengah pedalaman adalah Kecamatan Nanga Tayap,. Pada kelompok Selatan Pedalaman Kabupaten Ketapang posisi pertama adalah Kecamatan Marau. Hal ini dipilih terutama karena adanya fasilitas puskesmas rawat inap.

\section{V.SIMPULAN DAN SARAN}

Berdasarkan telaah dokumen yang ada dan telah dilakukan Skoring maka didapatkan empat lokasi yang bisa ditelaah lebih dalam yaitu Kecamatan Sandai dan Sungai Laur di utara Pedalaman, Kecamatan Nanga Tayap mewakili wilayah tengah pedalaman dan Kecamatan Air Upas mewakili selatan pedalaman Kabupaten Ketapang. Telaah dokumen di kajian awal ini akan jauh lebih baik untuk dapat ditelaah lebih dalam dengan melakukan focus group discussion (FGD) untuk melakukan pembobotan sehingga variabel yang ada dapat ditentukan prioritasnya sehingga bisa memastikan lokasi fasilitas kesehatan lebih lanjut(FKTL) yang lebih baik untuk mewakili utara, tengah dan selatan pedalaman Kabupaten Ketapang. Setelah itu barulah dilanjutkan dengan studi kelayakan secara utuh untuk mendukung realisasi 
adalnya FKTL di laokasi-lokasi yang sebelumnya dibahas.

\section{DAFTAR PUSTAKA}

Dinas Kesehatan Kabupaten Ketapang. Profil Kesehatan Kabupaten

Ketapang Tahun 2018, 2019

Dinas Kesehatan Provinsi Kalimantan Barat. Profil Kesehatan Provinsi Kalimantan Barat 2018, 2019

Dinas Kesehatan Kabupaten Ketapang. Statistik Kesejahteraan Kabupaten Ketapang 2019, 2020

Departemen Kesehatan Republik Indonesia. Pedoman dan teknis penyusunan Studi Kelayakan Rumah Sakit, 2012

Kementerian Kesehatan Republik Indonesia. Hasil Utama Riskesdas 2018 Provinsi Kalimantan Barat, 2018 